\title{
The Life of Ethnic Minorities of the Border Area and Cross-border Flows
}

\author{
Jingyi Wang \\ Yunnan Normal University, Kunming, Yunnan, China
}

Keywords: Ethnic Minority; Inhabitants of the Border Area; Cross-Border Flow.

\begin{abstract}
Hekou is an autonomous county of Yao nationality located in the border area of Yunnan and Vietnam. The frequent cross-border movements here change peoples' lives, and exercise great influence upon local economy and culture. Taking $S$ village at the China-Vietnam border as an example, this paper analyzes cross-border flows of goods and people in ethnic minority communities in the border area and summarizes the rules and regulations in their lives.
\end{abstract}

\section{Introduction}

S village is affiliated with a village committee of the Hekou Yao Autonomous County, Honghe Hani and Yi Autonomous Prefecture, Yunnan Province. The village is surrounded by the middle reaches of the Nanxi River and the periphery of Dawei Mountain National Nature Reserve. It located in the long, narrow zone of the mountainous area between Dawei Mountain and Nanxi River. The village is about 0.6 kilometers from the south to the north; its land area is 0.26 square kilometers. The village is an immigrant village of Miao nationality. All villagers are Miao nationality except for two Dai nationality villagers. Before the outbreak of Sino-Vietnamese War in 1979, it belonged to a farm. After the end of the war, the area became landless because of landmine. After the establishment of Nanxi town in 1988, villagers migrated here. The village has a captain (village head), an accountant, a village representative and a doctor. Economic crops are the main source of villagers' income. In recent years, bananas and pineapple are the main economic crops. The most notable feature of $\mathrm{S}$ village is the cross-border flow, which includes three aspects: marriage and family members, agriculture, as well as commerce. The village is adjacent to a Miao village of the Republic of Vietnam. Villagers are kin to Shanpingba inhabitants. The common used Miao language, the kinship and superior regional advantages provide convenient conditions for cross-border movements. People here use different ways to communicate and cooperate and produces the phenomenon of cross-border flowing.

\section{The Cross-border Flow of Goods}

Since 1990s, Vietnam has been carrying out innovation and opening strategy to vigorously promote the development of economy. In ethnic minority communities of the border area, the economic demand has become the decisive reason for cross-border movements. The trade between dwellers of the border develops rapidly. S village is a good example. According to survey results, in S village, the cross-border flow of goods covers a wide range, including cross-border leasing, planting, trading and transportation. With the continuous development of border trade, the fruit, rice and corn planted in Vietnam are shipped to China, while the chemical fertilizers and agricultural chemicals produced in China are transported to Vietnam.

The assessment of pineapples is an example. The existence of "three turns", namely the intermediary of dealing, makes pineapples flow across the border between Vietnam and China. Pineapples are divided into big fruit, middle fruit and small fruit. The distinction is made according to the weight and number of eyes (one lump in the peel of pineapple is called an "eye") of the fruit. Big fruits usually have more than seven eyes; middle fruits have five to seven eyes; small fruits have five eyes. Generally speaking, if the number of large fruits in a field exceeds $20 \%$ of the total, the farmer can make money. If the number of small fruit exceeds $20 \%$ of the total, the farmer will lose money. 
The whole process of assessment goes as following. When the pineapple is about to ripe, the intermediary comes to check the pineapple. If the intermediary is satisfied with these pineapples, he or she will buy the whole field from the farmer and notify the boss. When the boss decides to buy pineapples, he or she will pay a small part of the gross price of pineapples, which is regarded as the deposit, to the intermediary. When pineapples turn yellow and start to ripen, the boss will go to the pineapple plantation personally. He can figure out the total weight of pineapples in the field, as well as the ratios of big fruit and small fruit. Then the total weight and the total price of pineapples are estimated. The "three turns" are middle men who realize the cross-border trade of pineapples. They buy fruits from farmers, usually according to the cost of each kilogram; then sell the goods to bosses. If the fruits are planted by Vietnamese farmers, the process of transportation from Vietnam to China will be added. Generally, some Vietnamese are hired to carry fruits on their backs, and then walk from the field to vans at the ferry. Through them, pineapples planted by Vietnamese farmers flow into the Chinese market.

\section{The Cross-border Flow of People}

In recent years, more and more young women in S village leave their hometown and reluctant to come back. They choose to work outside, or marry someone who lives far away from here. It is difficult for young men to get married. Meanwhile, the village has a long border line, a large number of channels and high population mobility; the living customs of people live in the two countries are similar. The possibility of cross-border marriage raises to a great extent.

According to the survey, in S village, the main pattern of cross-border flow of people is the cross-border marriage. Young local women tend to go to work outside and refuse to live in the village. Meanwhile, local people contact with Vietnamese villagers frequently. Transnational marriages come into being under that situation. In $\mathrm{S}$ village, the marriage of five couples are transnational.

I married a Vietnamese wife. [1] My wife is a Vietnamese. At first, her family didn't agree with our marriage. But she liked me and wanted to live with me. When I went to her house in Vietnam, she came here for me. I gave her family one thousand yuan as the cash gift. We've lived together for ten years, but we still can't get the marriage license. Vietnam stipulates that, the conditions for getting a marriage license are Chinese identity card and residence booklet. My wife has been living in China for ten years. Her residence in Vietnam has been canceled. There is no way to get marriage certificate in Vietnam. In China, we do not have marriage certificate, either, since she does not have the residence booklet. Without a marriage certificate, our children cannot get registration. We have two kids; the older one is seven years old. He cannot go to the primary school because he does not have registered permanent residence. The same situation can be handled in Maguan and Qiaotou, but not here. In Maguan, the fine for two children is one thousand yuan. But in Hekou, the fine for one child is two thousand. Now I give up for my wife's registration, but children's residence must be obtained. Without the registered permanent residence, my children cannot go to school or get preventive inoculation.

In the course of investigation, we communicate with Vietnamese wives in the village. But they can say Miao language rather than Chinese. Only the wife of the village head can understand a little Chinese. The conversation is difficult to be carried. Five Vietnamese wives in the village do not have registered permanent residence; one of them do not have children, so they adopt a little girl. It can be seen that the cross-border movements of people are mainly marriage and blood relation. Their contacts and communication with neighboring Vietnamese villages are not affected by the national boundary.

\section{Rules of Cross-border Flows}

In cross-border flows, ethnic minorities have their own rules and behavior patterns. Referring to Foucault's study of power, this paper analyzes these folk rules from three aspects: analysis perspective, the view of power and power structure. 


\subsection{Analysis perspective}

In anthropology, field survey is the most basic way to obtain research data. It is the process of "obtaining first-hand research data through direct observation, interview, living experience and so on." [2] Traditional fieldwork usually takes a natural village as the basic unit of investigation. Researchers eat and live with local people and get related information through interviews and participation. Sanpingba group is located at the southeastern part of Yunnan and is adjacent to Lào Cai Province of Vietnam. It is also the smallest unit of administrative divisions in China. Investigation and research are carried out from villagers' daily life. Rules and regulations about food, clothing, housing and transportation are collected.

During the survey, three fruit transactions are conducted. Three turns get involved in two of them. Based on the investigation of farmers, three turns, transporters and bosses, the characteristics and behaviors of three turns as the intermediaries are concluded. The first condition is, three turns should be local villagers. He (she) knows all situations about banana and pineapple planting of every household. The rural society is a tiny acquaintance community. Three turns have dealing experience; most households trust them. Without three turns, there is no way to sell goods. On the other hand, all fruit bosses are outsiders. They need to know all kinds of goods and information through three turns. Thus, three turns are the best starting point for analyzing the rules of cross border flows. Through three turns, we can find out how the cross-border flow is generated, carried out and sustained.

The existence of intermediary is the result of folk border trades. Meanwhile, three turns promote the development of new folk border trades. The most typical example is that the dealing of pineapples have changed from weighing to assessment.

\subsection{Rules in cross-border flows (power)}

Firstly, these rules form a relational network. The life of all villagers live in the border area is a complex power network, which involves economic, political and cultural factors. All members are included in the network. Under different situations, villagers can become the subject or the object of power. The example of a ferry is used to explain this idea. The ferry is not established in accordance with relevant provisions and laws. According to villagers' description, there are different gangs and ways of actions in the ferry. The ferry involves the interests of different groups of people; some of them are Chinese while some are Vietnamese. During our investigation, a larger ferry on the Nanxi River, commonly known as the "Bazi River", was unable to load during the day due to some reasons. So at night, "Bazi River" became quite lively. During the survey period, a villager worked at the river in the evening. He told us that they must load 100 tons of grain at night. Border minority families are the same. They have their own rules of marriage and family life. Through investigation, it is also found that a villager had divorced once. When he divorced, his wife took away all the property. The whole process of divorce is "relatives and friends sat down and made judgments, then the property ownership is decided."

Secondly, the rules of cross-border flow are related with knowledge. When it comes to the relationship between rules and knowledge, the most notable example is existence of three turns. Here, knowledge is defined in a broad sense. In above analysis, we have introduced the transaction of pineapples. In this process, the figure of three turns has become the main body of power in the trading network. Three turns serve as the intermediary and hold the initiative position when dealing with farmers and bosses. Farmers plant a large number of economic crops; their lives depend entirely on transactions. Therefore, pineapple dealing is related to the basic livelihood of farmers; but most households do not have the marketing channel. On the other hand, fruit bosses are outsiders. They need to know more about the local situation through three turns. Therefore, three turns become the subject of power in the relationship of purchase because of their relatively unique knowledge on local conditions. Meanwhile, knowledge about natural condition, geographical environment, government policy and other related issues is also related to the estimated profit of pineapples.

Thirdly, the rules of cross-border flows are related to space. Space can be understood as different regions, communities and scenes. The dimension of space helps to build the network of power relations. Transnational marriages can be used to analyze this issue. There are many reasons for the 
emergence of transnational marriages. The main reasons are: young local women go outside for work and study; Chinese girls have relatively higher demands for life than Vietnamese girls. Local young men, especially those who live in the village, choose to marry Vietnamese girls. Transnational marriage appears in this area. Young men are the subjects of power when they choosing their partners. But transnational marriage brings a lot of problems, which transform the subjects of power into the objects of power. Without marriage certificates, wives and children cannot get their residence; other problems in children rearing will also become their plight in the future.

Minorities who live in the border area choose to live between the national laws and folk laws; their choice is the process and result of micro power from a deeper level. The compliance and implementation of national laws has a cost. When villagers cannot afford, they will choose folk rules to survive. At that time, they change from the objects of power to the subjects of power. In this situation of folk rules, a variety of power relations are created. They intertwine and influence each other, and are reflected in all aspects of villagers' lives.

\section{References}

[1] The passage is compiled from accounts given by a villager at his home on January 15, 2013.

[2] K.Z. Zhuang, The General Theory of Anthropology, Shanxi Education Press, Taiyuan, 2007. 